Document downloaded from:

http://hdl.handle.net/10251/105367

This paper must be cited as:

Irastorza, RM.; D Avila, A.; Berjano, E. (2018). Thermal Latency adds to Lesion Depth after Application of High-Power Short-Duration Radiofrequency Energy: Results of a computermodeling study. Journal of Cardiovascular Electrophysiology. 29(2):322-327. doi:10.1111/jce.13363

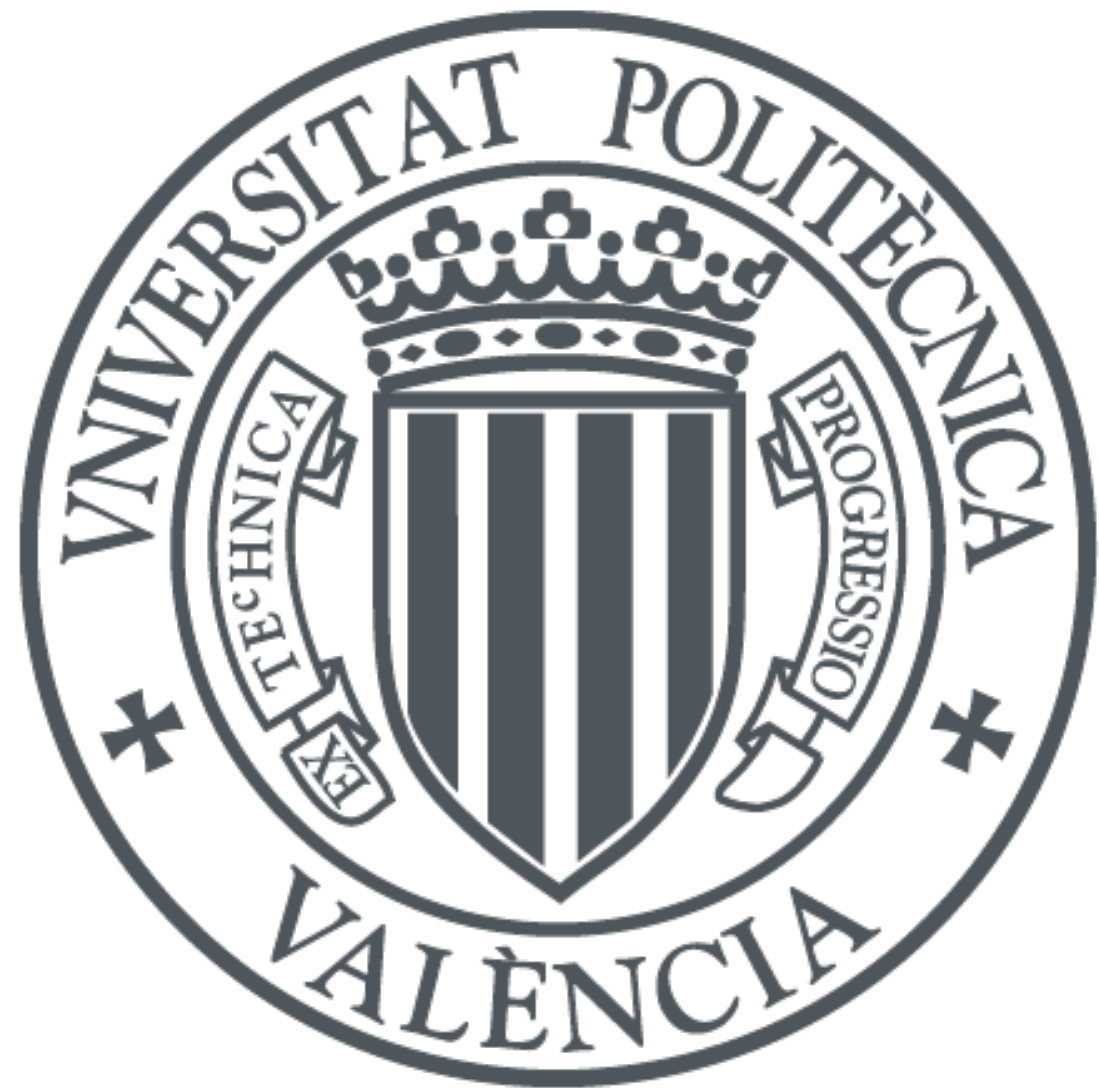

The final publication is available at

https://doi.org/10.1111/jce.13363

Copyright Blackwell Publishing

Additional Information 


\title{
Thermal Latency adds to Lesion Depth after Application of High-Power Short-Duration Radiofrequency Energy:
}

\author{
Results of a computer-modeling study
}

\author{
RAMIRO M. IRASTORZA, M.Sc, PH.D ${ }^{1,2}$, ANDRE D'AVILA, M.D., PHD ${ }^{3}$, and \\ ENRIQUE BERJANO, M.SC, PH.D ${ }^{4}$
}

\begin{abstract}
From ${ }^{1}$ Instituto de Física de Líquidos y Sistemas Biológicos (CONICET), La Plata, Argentina
${ }^{2}$ Instituto de Ingeniería y Agronomía, Universidad Nacional Arturo Jauretche, Florencio Varela, Argentina, ${ }^{3}$ Hospital Cardiologico, Florianopolis - SC, Brazil, ${ }^{4}$ BioMIT, Department of Electronic Engineering, Universitat Politècnica de València, Valencia, Spain,
\end{abstract}

Corresponding author: Dr. Enrique Berjano, Department of Electronic Engineering (Building 7F), Universitat Politècnica de València, Camino de Vera, 46022 Valencia, Spain; Email: eberjano@eln.upv.es

Financial support: This work was supported by the Spanish "Plan Estatal de Investigación, Desarrollo e Innovación Orientada a los Retos de la Sociedad” under Grant TEC2014-52383-C3 (TEC2014-52383-C3-1-R) and by the National Scientific and Technical Research Council Argentina “Proyecto de Investigación Orientado” (PIO CONICET-UNAJ 0001).

Declaration of interest: The authors have no conflicts of interest or financial disclosures to make relevant to this submission. 


\begin{abstract}
Introduction: The use of ultra-short RF pulses could achieve greater lesion depth immediately after the application of the pulse due to thermal latency.

Methods and results: A computer model of irrigated-catheter RF ablation was built to study the impact of thermal latency on the lesion depth. The results showed that the shorter the RF pulse duration (keeping energy constant), the greater the lesion depth during the cooling phase. For instance, after a 10-s pulse, lesion depth grew from $2.05 \mathrm{~mm}$ at the end of the pulse to $2.39 \mathrm{~mm}$ (17\%), while after an ultra-short RF pulse of only $1 \mathrm{~s}$ the extra growth was $37 \%$ (from $2.22 \mathrm{~mm}$ to $3.05 \mathrm{~mm}$ ). Importantly, short applications resulted in deeper lesions than long applications (3.05 mm vs. $2.39 \mathrm{~mm}$, for 1- and 10-s pulse, respectively). While shortening the pulse duration produced deeper lesions, the associated increase in applied voltage caused overheating in the tissue: temperatures around $100^{\circ} \mathrm{C}$ were reached at a depth of $1 \mathrm{~mm}$ in the case of 1 - and 5-s pulses. However, since the lesion depth increased during the cooling period, lower values of applied voltage could be applied in short durations in order to obtain lesion depths similar to those in longer durations while avoiding overheating.

Conclusion: The thermal latency phenomenon seems to be the cause of significantly greater lesion depth after short-duration high-power RF pulses. Balancing the applied total energy when the voltage and duration are changed is not the optimal strategy since short pulses can also cause overheating.
\end{abstract}

Key Words: cardiac ablation, computer model, RF ablation, thermal latency 


\section{Introduction}

There is a current tendency towards shortening the duration of the radiofrequency (RF) application during the ablation of atrial fibrillation, ${ }^{1}$ which obviously has to be accompanied by higher applied power to achieve a suitable lesion depth. Since atrial wall thickness is $\sim 2 \mathrm{~mm}$, a depth around this value could be enough to produce transmural lesions. The potential advantages of the shorter duration would be: 1) to reduce total procedural time, 2) reduce the saline volume infused through catheter irrigation, and 3) reduce possible complications, such as steam pops. ${ }^{1}$ From a biophysical point of view, using very short RF pulses would mean that the size of the thermal lesion depends almost exclusively on the electrical energy deposited (Specific Absorption Rate, $\mathrm{W} / \mathrm{m}^{3}$ ), instead of on the thermal conduction phenomenon. In theory, the thermal lesion size would thus depend on the electrical conductivity of the tissue and not on its thermal conductivity; and the lesion would be created instantly, for as long as the pulse lasts. However, this might not be so simple if the thermal latency phenomenon after short RF-pulses (5-10 s) remains

relevant. ${ }^{2}$ Thermal latency implies that tissue temperature continues to rise after termination of the RF application. Our goal was thus to determine the behavior of the thermal latency phenomenon after short RF applications in a computer model. ${ }^{3-5}$ Even though previous computer results have not shown thermal latency to have a significant role in determining lesion size after long RF applications, ${ }^{5}$ we hypothesized that it could play a different role after very short RF pulses.

\section{Methods}

As this study used a computational model, consequently no ethical approval was 
required. Fig. 1(a) shows the computational domain of the model developed, which included a fragment of atrial wall (1.5 mm thickness) and a 7-Fr 3.5-mm long irrigated electrode placed perpendicularly on the endocardium (0.5 $\mathrm{mm}$ insertion depth) and surrounded by blood. The domain is completed with a sufficiently large fragment of connective tissue. Fig. 1(b) shows the boundary conditions required to solve the problem. The dispersive electrode (voltage at zero volts, $\mathrm{U}=0 \mathrm{~V}$ ) is assumed to be on the boundaries of the connective tissue and at a sufficient distance from the active electrode. These boundaries represent a surface of $\sim 150 \mathrm{~cm}^{2}$, which approximately coincides with the area of a standard dispersive electrode. The temperature distribution within the tissue was obtained by solving the bioheat equation. ${ }^{6}$ Table 1 shows the physical characteristics of the tissues and materials employed in this model. ${ }^{3,7-8}$ The irrigated electrode was modeled by fixing a value of $40^{\circ} \mathrm{C}$ in the cylindrical zone of the electrode tip while RF is activated (see gray zone in Fig. 1(b)), and leaving it free once RF stops. The temperature at the semispherical tip was not fixed (free at all times). ${ }^{3}$ The thermal effect of the circulating blood in the cardiac chamber (assuming high flow) was modeled using thermal transfer coefficients between blood and the tissue $\left(\mathrm{h}_{\mathrm{T}}=610 \mathrm{~W} / \mathrm{m}^{2} \mathrm{~K}\right)$ and between blood and the electrode $\left(\mathrm{h}_{\mathrm{E}}=\right.$ $\left.3346 \mathrm{~W} / \mathrm{m}^{2} \mathrm{~K}\right){ }^{6}{ }$ Intramyocardial perfusion was assumed to be $1026 \mathrm{ml} / \mathrm{min} / \mathrm{kg}^{7}$ and to cease irreversibly once tissue was completely damaged. In contrast, the blood perfusion in the connective tissue was discarded, due to its being negligible compared to the cardiac tissue (37 vs. $1026 \mathrm{ml} / \mathrm{min} / \mathrm{kg}$ ). ${ }^{7}$ Both the initial temperature and the temperature of the surfaces away from the active electrode were initially assumed to be $37^{\circ} \mathrm{C}$. The latent heat associated with tissue vaporization at a temperature of $100^{\circ} \mathrm{C}$ was included in the model by applying the enthalpy method. ${ }^{5}$ 
The COMSOL Multiphysics program (COMSOL, Burlington MA, USA) was used to create the Finite Element Model and the computer simulations. Convergence tests were conducted to obtain the optimal outer dimensions of the model and meshing size. We simulated an RF pulse of duration $\mathrm{t}_{\mathrm{ON}}$ followed by a period $\mathrm{t}_{\mathrm{OFF}}$ of $200 \mathrm{~s}$, during which it was expected that tissue temperature would continue to rise due to thermal latency. The preliminary simulations confirmed that that after $200 \mathrm{~s}$ without applying RF power, the maximum temperature in the tissue fell below $37 \cdot 1^{\circ} \mathrm{C}\left(37^{\circ} \mathrm{C}\right.$ being the basal temperature).

High-power short-duration ablations were modeled by means of applying a voltage between the irrigated and the dispersive electrode during an interval ton. Once the temperature distributions had been computed using the bioheat equation, a mathematical function was used to estimate the thermal damage. Although it is broadly recognized that the $50-56^{\circ} \mathrm{C}$ isotherm can be used to delimit the lesion formation volume, this is only true for hyperthermic exposure times of several minutes, it would also be valid for $60 \mathrm{~s} .{ }^{9}$ For shorter exposure times the 'lethal' isotherm will possibly be higher. In any case, as we were interested in computing the thermal lesion size due to the accumulated thermal effect not only during $\mathrm{t}_{\mathrm{ON}}$ (when the tissue is really heated) but also during $\mathrm{t}_{\mathrm{OFF}}$, it was necessary to use a mathematical function which took into account not only the temperature reached but also the exposure time. We thus chose the Arrhenius function, which can compute the thermal damage parameter $\Omega$ over time. This parameter corresponds with the logarithm of the ratio of the original concentration of native tissue to the remaining native state tissue. A value of $\Omega=1$ means a $63 \%$ probability of cell death and can provide a reasonable definition of the size of the thermal lesion. Accordingly, we assumed that once the tissue reached a value $\Omega=1$ the blood perfusion ceased at that point. Further information on the 
mathematical formulation and the parameter values used to compute thermal damage are provided in the supplementary file. The impact of thermal latency was assessed by comparing the temperature distributions and the lesion depths just at the end of the RF pulse ( $\left.\mathrm{t}_{\mathrm{ON}-\mathrm{RF}}\right)$ with those computed after a longer duration ( $\left.\mathrm{t}_{\mathrm{ON}-\mathrm{RF}}+\mathrm{t}_{\mathrm{POST}-\mathrm{RF}}\right)$.

We also modified the model shown in Fig. 1 to mimic the experimental conditions in the study by Wittkampf et al., ${ }^{2}$ who used a dry electrode (7 Fr, $4 \mathrm{~mm}$ ) to apply short-duration (5 s) voltage pulses on a preparation of skeletal muscle and measured the temperature evolution at the electrode tip at depths of approximately 2, 4, and $7 \mathrm{~mm}$. The characteristics of the skeletal muscle used in the simulations were: electrical conductivity $\sigma$ of $0.28 \mathrm{~S} / \mathrm{m}^{10}$ thermal electrical $k 0.56$ of $\mathrm{W} / \mathrm{m} \cdot \mathrm{K},{ }^{7}$ specific heat $c$ of $2624 \mathrm{~J} / \mathrm{kg} \cdot \mathrm{K},{ }^{7}$ and density $\rho$ of 1090 $\mathrm{kg} / \mathrm{m}^{3}{ }^{7}$ We simulated a $40 \mathrm{~V}$ pulse, which implied an applied power of $\sim 14 \mathrm{~W}$ (over an electrical impedance of $115 \Omega$ ). This power value is lower than that used by Wittkampf et $a l^{2}$ since our computational domain only considered a part of the real physical domain. As in Wittkampf et al., ${ }^{2}$ we analyzed the progress of the temperatures measured at depths of 2and 4-mm, and calculated three characteristics associated with the thermal latency: 1) timing of maximum temperature, 2) time between termination of the pulse and point at which temperature returned to end-of-pulse value, and 3) additional rise in temperature after the pulse. In order to check the likely thermal effect of the temperature probes used by Wittkampf et al., ${ }^{2}$ the optical fibers $\left(200 \mu \mathrm{m}\right.$ hard clad silica fiber with Tefzel ${ }^{\circledR}$ jacket) were realistically modeled as a tiny sphere (100 $\mu$ m radius) representing the silica glass ( $\sigma$ $=10^{-13} \mathrm{~S} / \mathrm{m}, k=1.0 \mathrm{~W} / \mathrm{m} \cdot \mathrm{K}, c=850 \mathrm{~J} / \mathrm{kg} \cdot \mathrm{K}, \rho=2625 \mathrm{~kg} / \mathrm{m}^{3}$ ) surrounded by a concentric layer of Teflon $\left(150 \mu \mathrm{m}\right.$ thick) representing the plastic jacket $\left(\sigma=10^{-6} \mathrm{~S} / \mathrm{m}, k=0.24\right.$ 
$\mathrm{W} / \mathrm{m} \cdot \mathrm{K}, c=300 \mathrm{~J} / \mathrm{kg} \cdot \mathrm{K}, \rho=1700 \mathrm{~kg} / \mathrm{m}^{3}$ ), hence creating a total outer diameter of $5 \mathrm{~mm}$.

\section{Results}

The outer dimensions of the model ( $\mathrm{X}$ and $\mathrm{Y}$ ) were checked using a sensitivity analysis in which we assessed how location of $\Omega=1$ isoline was modified when $\mathrm{X}$ and Y were equally enlarged. An optimal value of $\mathrm{X}=\mathrm{Y}=40 \mathrm{~mm}$ was determined, since an additional increase of $1 \mathrm{~mm}$ meant that the $\Omega=1$ isoline shifted less than $0.1 \mathrm{~mm}$. The same procedure was conducted to obtain the optimal meshing size, which ranged from $200 \mu \mathrm{m}$ (at the electrodetissue interface) to $1 \mathrm{~mm}$ (on the outer dimensions of the model). The models had around 4,000 elements and a time-step of $0.1 \mathrm{~s}$.

Once the model had been appropriately modified to mimic the experimental conditions of a previous study, ${ }^{2}$ we computed the evolution of temperature at the electrode tip and depths of $2 \mathrm{~mm}$ and $4 \mathrm{~mm}$. The modified model was able to reproduce satisfactorily both $t_{\max }$ and $t_{d u r}$ at a depth of $2 \mathrm{~mm}$ (see Table 2), but unfortunately could not do the same with $\Delta \mathrm{T}$ or the thermal behavior at $4 \mathrm{~mm}$. Despite this, the model was on the whole able to reproduce the phenomenon of thermal latency observed in the experiments (as shown in Fig. 2). Finally, the results obtained when the optical fibers were included in the model were almost identical to those obtained without them.

Figure 3 shows the temperature distributions at different times after application of a 5-s RF pulse. Although thermal latency has been known to raise tissue temperatures after the RF pulse has ceased (see e.g. Fig. 2), the maximum temperatures (see Fig. 3) were computed exactly at the termination of RF delivery (Fig. 3a). However, as can be seen in Fig. $3 \mathrm{~b}$, the tissue temperature is still high $\left(\sim 70^{\circ} \mathrm{C}\right) 5 \mathrm{~s}$ after termination (Fig. 3b). 
Furthermore, the hottest point is now inside the tissue as the cooling phase progresses, which appears to indicate that the thermal lesion is getting deeper. This is evident from the evolution of the thermal damage contours (dashed lines in Fig. 3). Interestingly, the increased width of the lesion is almost negligible compared to the depth. Figure 3 also suggests that with a 5-s RF pulse, the thermal lesion depth almost reached its maximum value $10 \mathrm{~s}$ after RF pulse cessation (Fig. 3c).

In this respect, Fig. 4a shows the progress of the thermal depth for different RF pulse durations keeping the delivered energy constant. It can be seen that the shorter the RF pulse duration, the deeper the lesion depth during the cooling phase. For instance, for a 10-s pulse, lesion depth is $2.05 \mathrm{~mm}$ right at the end of the pulse, and then grows by $17 \%$ to 2.39 mm. For an ultra-short RF pulse of only $1 \mathrm{~s}$, the lesion depth grows by 37\% from $2.22 \mathrm{~mm}$ to $3.05 \mathrm{~mm}$. More importantly, the results also revealed that short applications result in deeper lesions than long applications (even though the different combinations of voltagetime considered were purposely chosen to match the applied total energy): 2.39, 2.81 and $3.05 \mathrm{~mm}$, for 10-, 5- and 1-s pulse, respectively, which implied an increase of $28 \%$ between 1- and 10-s pulses. Note that lesion depths were almost identical at the end of each pulse: 2.22, 2.16 and $2.05 \mathrm{~mm}$, for 1-, 5- and 10-s pulse, respectively. The differences found (less than $10 \%$ ) were due to the change in electrical conductivity during heating, which involved minor differences in the applied total energy (146, 143 and $140 \mathrm{~J}$, for 1-, 5- and 10-s pulse, respectively).

While shortening the pulse duration allowed enlarging the lesion depth, the associated increase in applied voltage caused overheating in the tissue. Fig. $4 \mathrm{~b}$ shows the progress of the tissue temperature for different RF pulse durations assessed at a depth of $1 \mathrm{~mm}$ (which 
was the maximum value reached in the tissue). The high values of applied voltage employed in the case of 1 - and 5-s pulses caused temperatures around $100^{\circ} \mathrm{C}$, which would coincide with the appearance of steam pops. Since this phenomenon has to be avoided for the sake of safety, we used computer simulations to determine how applied voltage could be appropriately reduced to reduce the number of steam pops and at the same time ensure that lesion depth remained at values similar to those obtained with longer pulses. The idea behind this is that lesion depth can increase during cooling and can compensate for using a lower applied voltage. In this respect, Fig. 5a shows the progress of the thermal depth for different RF pulse durations when the applied voltage is chosen to obtain the same lesion depth $(\sim 2.4 \mathrm{~mm})$. Fig. 5b shows the progress of tissue temperature for different RF pulse durations assessed at a depth of $1 \mathrm{~mm}$. In this case the value of the applied voltage employed for a 1-s pulse did not cause temperatures of $100^{\circ} \mathrm{C}$, which suggests that it is possible to shorten the RF pulse, to increase the applied voltage, and simultaneously avoid steam pops. Therefore, the results also suggest that balancing the applied total energy is not the optimal strategy, since steam pops can still occur.

\section{Discussion}

The phenomenon of thermal latency was initially introduced in an attempt to explain the unintentionally induced atrioventricular delay occasionally observed subsequent to RF application near the atrioventricular node. ${ }^{2}$ This finding also showed that this phenomenon was only relevant for short pulses of less than $10 \mathrm{~s}$ and the study did not have a great impact since RF ablations have employed longer durations (1-2 minutes) for many years. However, as it has recently been proposed to shorten RF pulse duration for atrial ablations, 
we considered that thermal latency merited a review in terms of exploring how this phenomenon increased lesion depth just after RF application. This fact is clearly relevant, since very shallow lesions are required under certain conditions due to the extreme thinness of the atrial wall.

Firstly, the present results confirmed that computer modeling can effectively reproduce the additional rise in tissue temperature after termination of RF delivery, i.e. the thermal latency phenomenon as described by Wittkampf et al. ${ }^{2}$ The differences between the experimental and computer results (Table 2) could be due to the inaccuracy in the position of the temperature probes in the tissue during the experiments.

Since thermal damage is a process involving both temperature and time, it is by no means straightforward to determine experimentally how lesion depth increases just after the application of a short-duration RF pulse. For instance, although a well-designed setup based on agar gel including a thermochromic sheet can be employed, as in Bhaskaran et al., ${ }^{1}$ this only provides temperature maps but not thermal damage contours. On the other hand, ex vivo and in vivo models can provide thermal damage contours, but are unable to differentiate between the contours created just at the end of the RF pulse and those produced at the end of the cooling phase. Computer modeling seems to provide a good alternative, since it can compute the degree of thermal damage at any time and is thus able to quantify the extra-growth produced just after RF application.

Our computer results revealed two important issues. Firstly, the shorter the RF pulse, the more the lesion depth increases during the cooling phase, i.e. the phenomenon of the thermal latency seems to be more relevant. For instance, for short pulses of $10 \mathrm{~s}$, lesion depth will increase by $17 \%$ during the cooling phase and the increase can be as much as 
37\% with ultra-short $1 \mathrm{~s}$ pulses. This finding has two important clinical implications: 1) since accidental thermal injury could occur in the esophagus up to several seconds after applying an ultra-short RF pulse, any system aimed at preventing this injury based on luminal esophageal temperature monitoring and the subsequent cessation of RF power once a limit temperature is reached would not be effective; and 2) any image-based technology used to monitor real-time lesion growth during an RF ablation ${ }^{11}$ should take into account the increased lesion depth after applying ultra-short RF pulses.

Secondly, we observed that shorter pulses created larger lesions, even though the applied total energy was more or less similar in all cases. The reason seems to be the higher temperatures associated with the use of high voltage in the case of short durations. Unfortunately, these high voltage values also involved a risk of overheating and the formation of steam pops. The computer results suggest that overheating could be avoided by reducing the applied voltage and at the same time lesions could be created comparable to those formed with long durations. Future experimental studies aimed to assessing the impact of high-power short-duration RF pulses on lesion volume and steam pops should take our computer results into account.

As limitations of this study, it should be mentioned that the irrigation electrode was modeled by an approximate method, which simplified the computation by ignoring the fluid dynamics problem, and blood circulation was not included in the model. Although this method is able to reproduce lesion depth and tissue maximum temperature fairly well, it fails to predict the blood temperature and the width of the surface lesion. ${ }^{3}$ This means that no conclusion can be reached regarding thrombus formation on electrode and tissue surfaces. However, it is reasonable to assume that both the electrode surface and the tissue 
surface will cool quickly thanks to the circulating blood in the cardiac chamber. Thermal latency does not therefore seem to favor the formation of thrombi. Future modeling studies including the fluid dynamics problem should be conducted to confirm this hypothesis. Experimental studies will also be required to assess the impact of the thermal latency associated with the use of short RF pulses on formation of thrombi, steam pops, and the created lesion volume.

\section{Conclusions}

When short-duration high-power RF pulses are used, the thermal latency phenomenon seems to add to lesion depth after RF application by as much as $37 \%$ for ultra-short $1 \mathrm{~s}$ pulses. As the increased lesion depth was probably due to overheating, balancing the applied total energy when the voltage and duration parameters are changed is not the optimal strategy. In fact, lower voltage can be set in the case of short durations in order to obtain the same lesion depth as that created with longer durations while avoiding overheating thanks to the increased lesion depth during cooling (especially important with short pulses).

\section{References}

1. Bhaskaran A, Chik W, Pouliopoulos J, Nalliah C, Qian P, Barry T, Nadri F, Samanta R, Tran Y, Thomas S, Kovoor P, Thiagalingam A: Five seconds of 50-60 W radio frequency atrial ablations were transmural and safe: an in vitro mechanistic assessment and force-controlled in vivo validation. Europace 2017;19:874-880.

2. Wittkampf FH, Nakagawa H, Yamanashi WS, Imai S, Jackman WM: Thermal latency in 
radiofrequency ablation. Circulation 1996;93:1083-6.

3. Pérez JJ, D'Avila A, Aryana A, Berjano E: Electrical and thermal effects of esophageal temperature probes on radiofrequency catheter ablation of atrial fibrillation: results from a computational modeling study. J Cardiovasc Electrophysiol 2015;26:556-64.

4. Pérez JJ, D'Avila A, Aryana A, Trujillo M, Berjano E: Can Fat Deposition After Myocardial Infarction Alter the Performance of RF Catheter Ablation of Scar-Related Ventricular Tachycardia?: Results from a Computer Modeling Study. J Cardiovasc Electrophysiol 2016;27:947-52.

5. Irastorza RM, Trujillo M, Berjano E: How coagulation zone size is underestimated in computer modeling of RF ablation by ignoring the cooling phase just after RF power is switched off. Int J Numer Method Biomed Eng 2017 Feb 1. doi: 10.1002/cnm.2869. [Epub ahead of print].

6. González-Suárez A, Berjano E: Comparative Analysis of Different Methods of Modeling the Thermal Effect of Circulating Blood Flow During RF Cardiac Ablation. IEEE Trans Biomed Eng 2016;63:2509.

7. Hasgall PA, Di Gennaro F, Baumgartner C, Neufeld E, Gosselin MC, Payne D, Klingenböck A, Kuster N: IT'IS Database for thermal and electromagnetic parameters of biological tissues, Version 3.0, September 01st, 2015, Doi: 10.13099/VIP21000-03-0. www.itis.ethz.ch/database.

8. Tungjitkusolmun S, Staelin ST, Haemmerich D, Tsai JZ, Webster JG, Lee FT Jr, Mahvi DM, Vorperian VR: Three-Dimensional finite-element analyses for radio-frequency hepatic tumor ablation. IEEE Trans Biomed Eng 2002;49:3-9.

9. Haines DE: Letter regarding article, "Direct measurement of the lethal isotherm for radiofrequency ablation of myocardial tissue". Circ Arrhythm Electrophysiol 2011;4:e67.

10. Epstein BR, Foster KR: Anisotropy in the dielectric properties of skeletal muscle. Med Biol Eng Comput 1983;21:51-5.

11. Herranz D, Lloret J, Jiménez-Valero S, Rubio-Guivernau JL, Margallo-Balbás E: Novel catheter enabling simultaneous radiofrequency ablation and optical coherence reflectometry. Biomed Opt Express 2015;6:3268-3275. 
Table 1. Physical characteristics of tissues and materials employed in computer model $[3,7,8]$.

\begin{tabular}{|c|c|c|c|c|c||}
\hline Tissue & $\sigma(\mathbf{S} / \mathbf{m})$ & $\boldsymbol{k}(\mathbf{W} / \mathbf{m} \cdot \mathbf{K})$ & $\boldsymbol{\rho}\left(\mathbf{k g} / \mathbf{m}^{3}\right)$ & $\boldsymbol{c}(\mathbf{J} / \mathbf{k g} \cdot \mathbf{K})$ & $\omega_{b} \mathbf{( 1 / \mathbf { s } )}$ \\
\hline Atrial wall (heart muscle) [7] & 0.28 & 0.56 & 1081 & 3686 & 0.018 \\
\hline Connective tissue [7] & $0.2^{*}$ & 0.39 & 1027 & 2372 & \\
\hline Cardiac chamber/Blood [8] & 0.667 & 0.54 & 1000 & 4148 \\
\hline Electrode/Pt-Ir [3] & $4.6 \times 10^{6}$ & 71 & $21.5 \times 10^{3}$ & 132 \\
\hline Catheter/Polyurethane [3] & $10^{-5}$ & 0.026 & 70 & 1045 & \\
\hline
\end{tabular}

$\sigma$ : electric conductivity; $k$ : thermal conductivity; $\rho$ : density; $c$ : specific heat; $\omega_{b}$ : blood perfusion.

* This value was adjusted in order to achieve a total impedance of $130 \Omega$.

Table 2. Comparison between experimental and computational results.

\begin{tabular}{|c|c|c|c|c|c|c|}
\hline & \multicolumn{2}{|c|}{$t_{\max }(s)$} & \multicolumn{2}{|c|}{$t_{\text {dur }}(s)$} & \multicolumn{2}{|c|}{$\Delta \mathrm{T}\left({ }^{\circ} \mathrm{C}\right)$} \\
\hline & $2 \mathrm{~mm}$ & $4 \mathrm{~mm}$ & $2 \mathrm{~mm}$ & $4 \mathrm{~mm}$ & $2 \mathrm{~mm}$ & $4 \mathrm{~mm}$ \\
\hline Experiments (from [2]) & 1.3 & 2.5 & 3.5 & 8.0 & 4.8 & 4.2 \\
\hline In silico model & 1.6 & 6.9 & 3.6 & 19.9 & 0.7 & 1.2 \\
\hline
\end{tabular}

$\mathbf{t}_{\text {max }}$ : timing of maximum temperature; $\mathbf{t}_{\text {dur }}$ : time between termination of the pulse and point at which temperature returned to end-of-pulse value; $\Delta \mathbf{T}$ : additional rise in temperature after the pulse. 


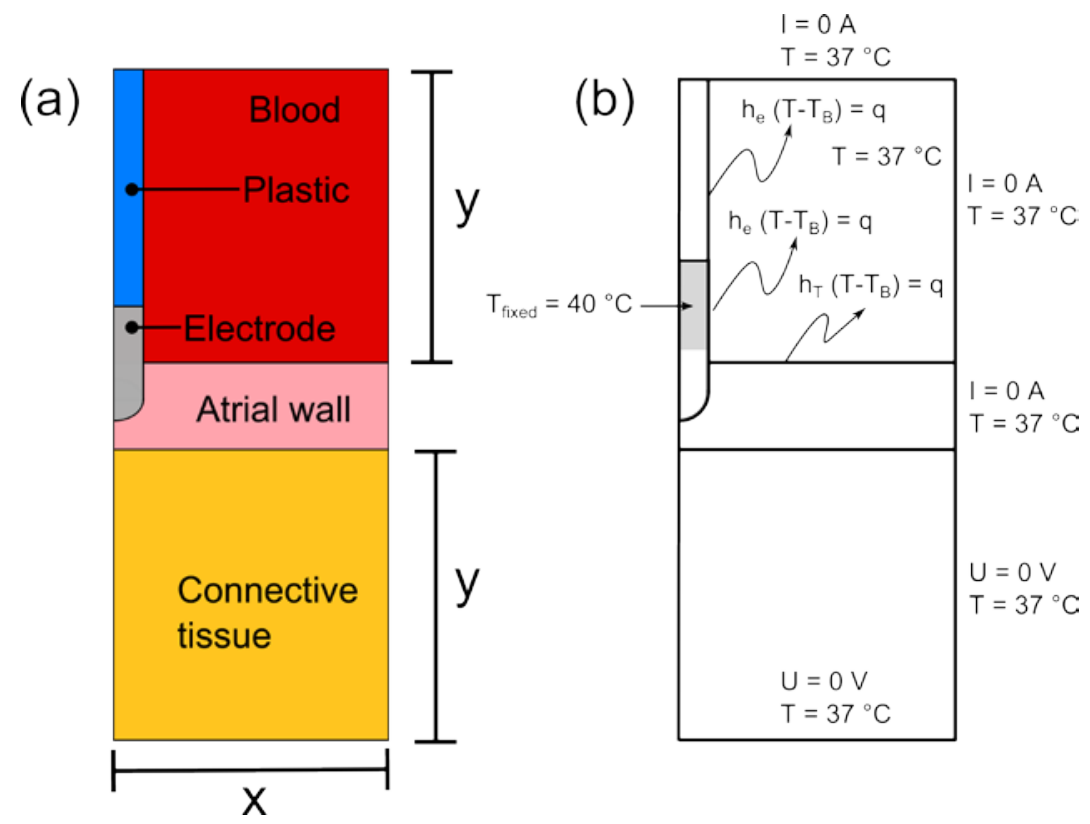

Figure 1 (a) Elements of the model (out of scale). (b) Electrical and thermal boundary conditions imposed in order to obtain a unique mathematical solution. 


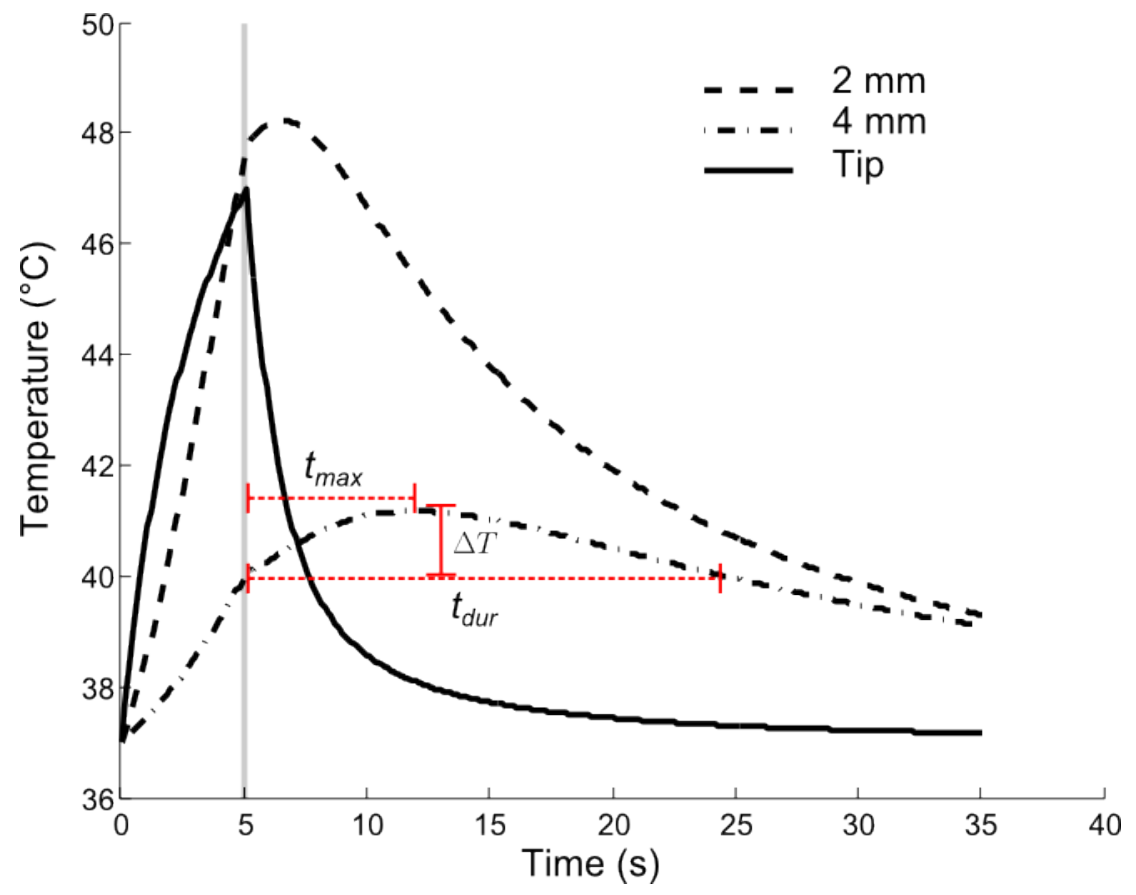

Figure 2 Temperature evolution computed at the electrode tip, and at depths of 2 and $4 \mathrm{~mm}$ by using an in silico model modified to mimic the experimental conditions of a previous study. ${ }^{2}$ Note the thermal latency characterized by a delayed rise in tissue temperature once the 5-s RF pulse has ceased. 


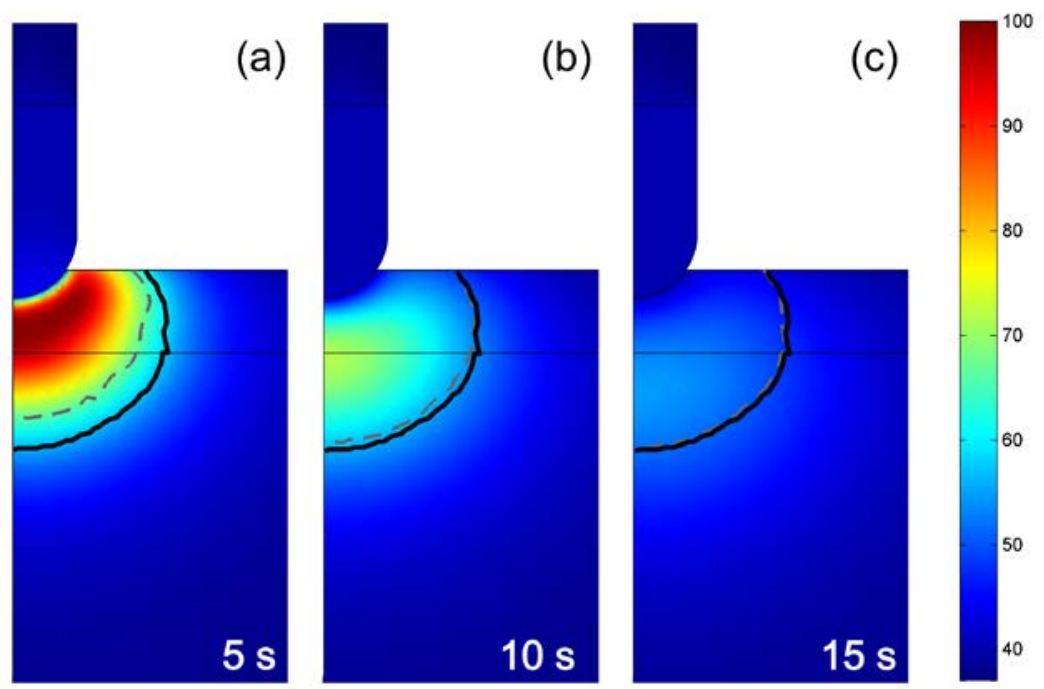

Figure 3 Temperature distributions after a 5-s RF pulse: (a) just at the end of RF pulse, (b) $5 \mathrm{~s}$ after RF was stopped, and (c) $10 \mathrm{~s}$ after RF was stopped. Scale in ${ }^{\circ} \mathrm{C}$. Dashed line is the thermal damage contour $(\Omega=1)$ assessed at each time, while the solid line is the thermal damage contour assessed at the end of the simulation $\left(\mathrm{t}_{\mathrm{ON}}+\mathrm{t}_{\mathrm{OFF}}=205 \mathrm{~s}\right)$. 

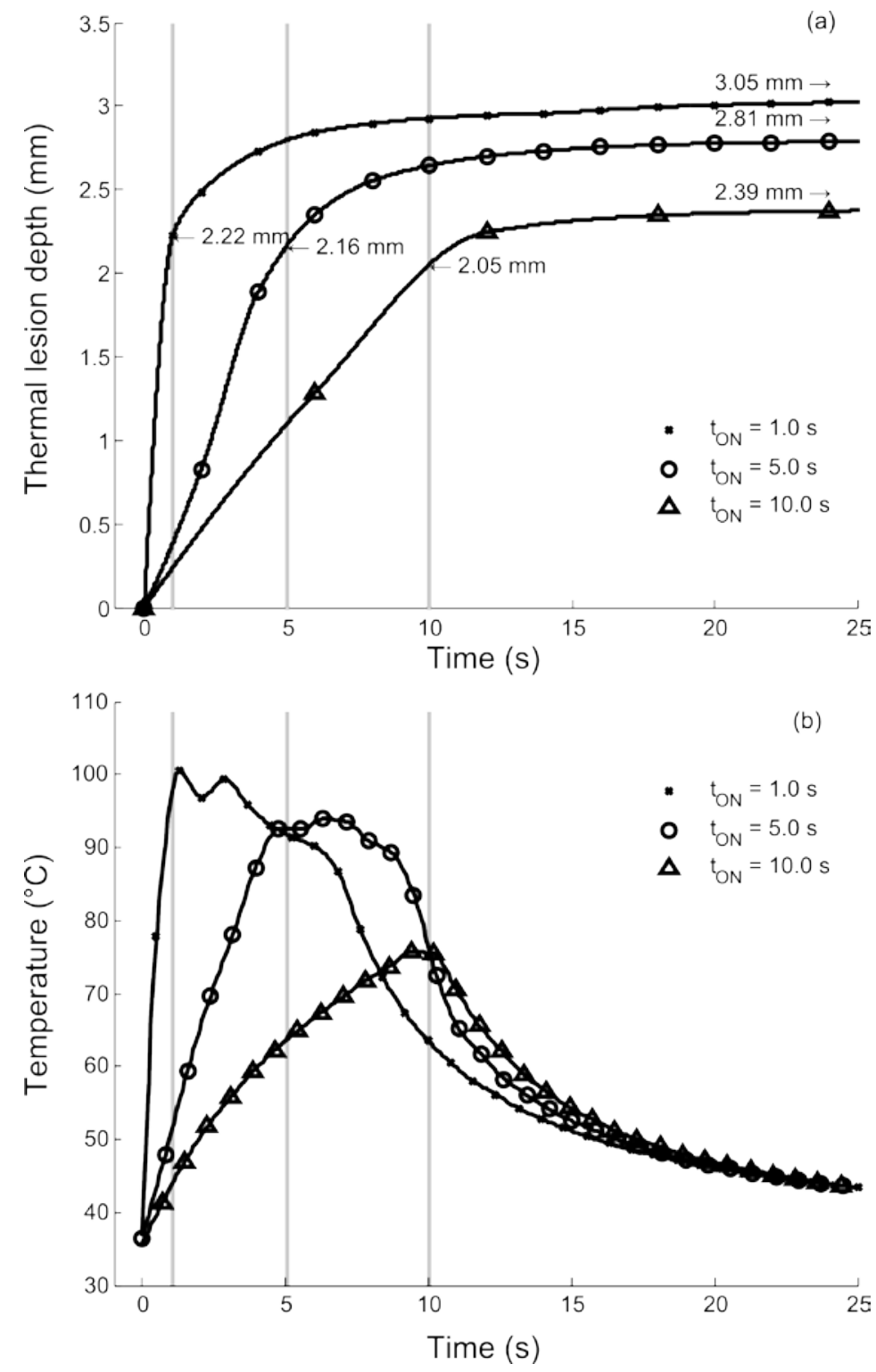

Figure 4 (a) Evolution of the thermal lesion depths for pulse durations of 1, 5 and 10 seconds. The applied voltage in each case was 134,60 , and $42 \mathrm{~V}$, respectively. These values were chosen in order to keep the delivered energy constant at 140 J. (b) Evolution of tissue temperature (1 mm depth) for different pulse durations. Note that steam pops (temperature around $100^{\circ} \mathrm{C}$ ) occur with the 1-s pulse. 

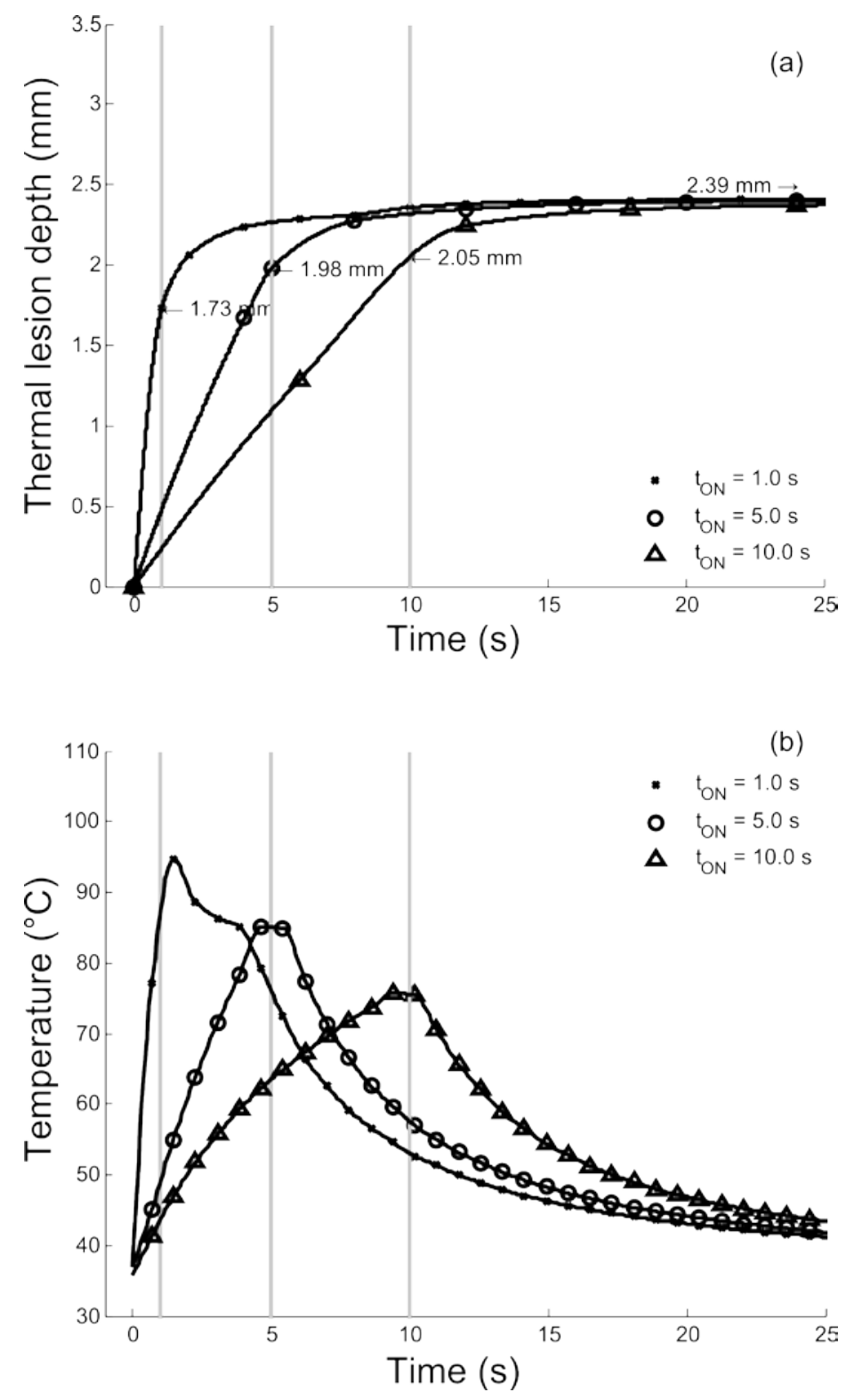

Figure 5 (a) Evolution of the thermal lesion depths for pulse durations of 1, 5 and 10 seconds. The applied voltage in each case was 112,56 , and $42 \mathrm{~V}$, respectively. These values were chosen in order to obtain a lesion depth of $\sim 2.4 \mathrm{~mm}$. (b) Evolution of the tissue temperature (1 mm depth) for different pulse durations. Note that the temperature does not reach $100^{\circ} \mathrm{C}$ in any case. 


\section{Supplementary file}

Details of the mathematical formulation used to compute thermal damage.

In order to compute the thermal damage, we chose the Arrhenius function, which allows the thermal damage parameter $\Omega$ to be computed over time $(t)$ as follows:

$\Omega(t)=\int_{0}^{t} A e^{\frac{-\Delta E}{R T(\tau)}} d \tau$

where $R$ is the universal gas constant (8.314 J/mole.K), $T$ is the absolute temperature (K), $t$

is time (s), $A\left(\mathrm{~s}^{-1}\right)$ is the frequency factor, and $\Delta E(\mathrm{~J} / \mathrm{mole})$ is the activation energy. We considered the both parameters ( $A$ and $\Delta E$ ) were constant over the entire temperature range.

Since the parameters $A$ and $\Delta E$ are specific for tissue type and damage process to be modeled, and their values in the literature vary enormously, we conducted a sensitivity analysis to determine the optimum values in the context of our objective. We checked the following tentative values: $A=3 \times 10^{23} \mathrm{~s}^{-1}$ and $\Delta E=1.62 \times 10^{5} \mathrm{~J} / \mathrm{mol},{ }^{1} A=5.6 \times 10^{63} \mathrm{~s}^{-1}$ and $\Delta E=4.3 \times 10^{5} \mathrm{~J} / \mathrm{mol}^{2}$, and finally $A=7.39 \times 10^{39} \mathrm{~s}^{-1}$ and $\Delta E=2.577 \times 10^{5} \mathrm{~J} / \mathrm{mol}^{3}$ This last pair of values has been widely used in computer modeling of RF ablation processes, even though it does not specifically refer to cardiac tissue. In order to find the optimum values, we assumed that the candidate values should be able to provide a $\Omega=1$ isoline more or less coincident with the $72^{\circ} \mathrm{C}$ isotherm for $5 \mathrm{~s}$ heating ${ }^{4}$ and more or less coincident with the $55^{\circ} \mathrm{C}$ isotherm after 60 seconds of heating. ${ }^{5-6}$

Figure S1 (a-c) shows the temperature distributions after $5 \mathrm{~s}$ of RF ablation for three groups of parameters related with the thermal damage parameter $\Omega$, while Figure S1 (d-f) shows the temperature distributions after $60 \mathrm{~s}$ of RF ablation. The results in Fig. 1S (a-c) 
suggest that the optimal parameters are those of the third set of parameters (from Irastorza et

al. ${ }^{3}$ ) since the $72^{\circ} \mathrm{C}$ isotherm is more or less coincident with the isoline $\Omega=1$ (differences smaller than $0.3 \mathrm{~mm}$ ). This is also confirmed in Fig. $1 \mathrm{~S}$ (d-f), since the $55^{\circ} \mathrm{C}$ isotherm obtained with the liver parameters is the nearest to the isoline $\Omega=1$. Consequently, the following parameters were chosen to compute the Eq. (1): $A=7.39 \times 10^{39} \mathrm{~s}^{-1}$ and $\Delta E=$ $2.577 \times 10^{5} \mathrm{~J} / \mathrm{mol}$.

\section{References for the supplementary file}

1. Agah R, Gandjbakhche AH, Motamedi M, Nossal R, Bonner RF. Dynamics of temperature dependent optical properties of tissue: dependence on thermally induced alteration. IEEE Trans Biomed Eng. 1996 Aug;43(8):839-46.

2. Diller KR, Valvano JW, Pearce JA: Bioheat transfer In Kreith F and Goswami DY eds: The CRC Handbook of Mechanical Engineering second edition. CRC PRESS, 2005, pp, 749-828.

3. Irastorza RM, Trujillo M, Berjano E. How coagulation zone size is underestimated in computer modeling of RF ablation by ignoring the cooling phase just after RF power is switched off. Int J Numer Method Biomed Eng. 2017 Feb 1. doi: 10.1002/cnm.2869. [Epub ahead of print].

4. Pearce JA. Comparative analysis of mathematical models of cell death and thermal damage processes. Int J Hyperthermia. 2013 Jun;29(4):262-80.

5. Haines DE. Letter regarding article, "Direct measurement of the lethal isotherm for radiofrequency ablation of myocardial tissue".Circ Arrhythm Electrophysiol. 2011 Oct;4(5):e67.

6. Thomsen S, Pearce JA, Randeri R. Determination of isotherms of thermal damage. Lasers and ElectroOptics Society Annual Meeting, 1994. LEOS '94 Conference Proceedings. IEEE: 295-6. 

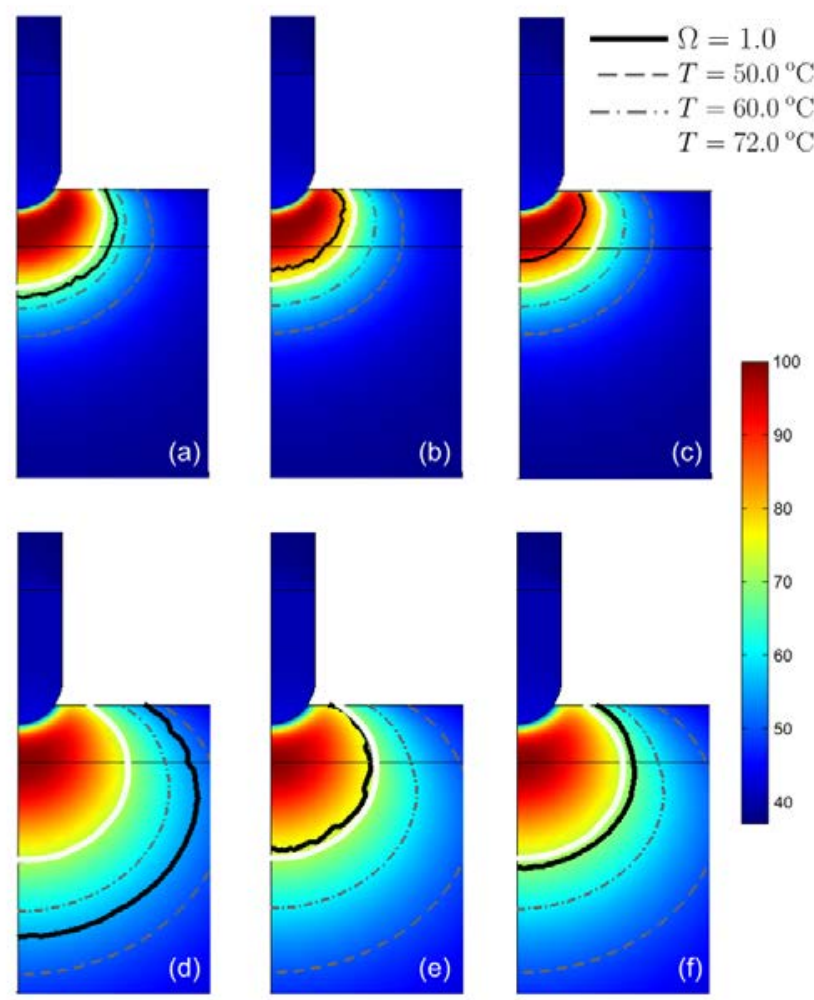

Figure S1 Temperature distributions after $5 \mathrm{~s}$ of RF ablation (a-c) and after $60 \mathrm{~s}$ of RF ablation (d-f). In the first set (a-c), the applied voltage was $60 \mathrm{~V}$, which corresponded with an applied power of $26 \mathrm{~W}$; while in the second set (d-f) was $40 \mathrm{~V}$. The scale is shown in ${ }^{\circ} \mathrm{C}$. The thick black solid line is the thermal damage contour $(\Omega=1)$ computed from the Arrhenius function using different values for the parameters $A$ and $\Delta E: A=7.39 \times 10^{39}$ $\mathrm{s}^{-1}$ and $\Delta E=2.577 \times 10^{5} \mathrm{~J} / \mathrm{mol}$ in (a) and (d); $A=5.6 \times 10^{63} \mathrm{~s}^{-1}$ and $\Delta E=4.3 \times 10^{5} \mathrm{~J} / \mathrm{mol}$ in (b) and (e); and $A=3 \times 10^{23} \mathrm{~s}^{-1}$ and $\Delta E=1.62 \times 10^{5} \mathrm{~J} / \mathrm{mol}$ in (c) and (f). 